NJE Vol. 35: 135-143, 2019

Nigerian Journal of Entomology

Published by the Entomological Soc. of Nig.

www.esnjournal.com.ng

DOI.10.36108/NJE/9102/53.01.21

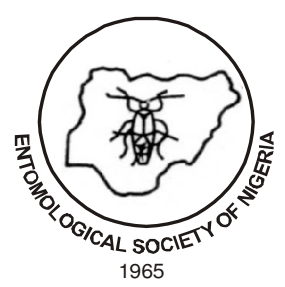

\title{
Food Host Preference and Life cycle characteristics of the Papaya mealybug, Paracoccus marginatus Will. and Granara de Willink in Ibadan, Southwest Nigeria
}

\author{
Okeke, A. S., ${ }^{1 *}$ Omoloye, A. A., ${ }^{1}$ Umeh, V. C. ${ }^{2}$ and Goergen, G. ${ }^{3}$ \\ ${ }^{1}$ Department of Crop Protection and Environmental Biology, University of Ibadan, Nigeria \\ ${ }^{2}$ National Horticultural Research Institute, Ibadan, Nigeria \\ ${ }^{3}$ International Institute of Tropical Agriculture, Cotonou, Benin
}

\begin{abstract}
Papaya mealybug, Paracoccus marginatus is an invasive polyphagous hemipteran that causes enormous damage to different host plants in Nigeria. However, information on the pest's damage potential and host range is scanty; therefore, the host preference and life cycle of $P$. marginatus were investigated. Six economic plants: Carica papaya (Caricaceae), Solanum lycopersicum (Soalnaceae), Manihot esculenta (Euphorbiaceae), Abelmoschus esculentus (Malvaceae), Psidium guajava (Myrtaceae) and Tectona grandis (Lamiaceae) were evaluated as food hosts to P. marginatus using free-choice and no-choice tests in screen cages $(1.80 \mathrm{x} 0.60 \mathrm{x} 1.50 \mathrm{~m})$. The developmental biology was investigated following standard procedures at ambient conditions of $27 \pm 2{ }^{\circ} \mathrm{C} ; 70 \pm 5 \% \mathrm{RH}$ and $12: 12$ hour photoperiod. Significantly more $P$. marginatus migrated to and utilized $C$. papaya $(27.5 \pm 2.9)$ and $M$. esculenta $(20.75 \pm 1.3)$ as food host. This pest occurred on other plants in decreasing order; $S$. lycopersicon $(17.0 \pm 1.3)>P$. guajava $(12.5 \pm 0.4)>A$. esculentus $(11.8 \pm 1.2)$ and $T$. grandis $(10.00 \pm 1.4)$ appeared to be the least preferred. The duration of development from egg to adult ranged from $23.52 \pm 0.1$ to $25.76 \pm 0.4$ days in the females and $25.91 \pm 0.6$ to $30.62 \pm 0.8$ in the males, which passed through more nymphal instars (4) than in females (3). The life cycle of $P$. marginatus was completed in shorter time on $C$. papaya than on any other host plants. The differences between male and female adult weights $(2.98 \pm 0.4 \mathrm{mg}$ and $3.90 \pm 0.6 \mathrm{mg})$ were not significant. Paracoccus marginatus preferred pawpaw and cassava to the other crops. This information is useful for development of appropriate integrated management programme for the pest.
\end{abstract}

Keywords: Carica papaya, Host plant preference, Life-cycle, Developmental biology, Paracoccus marginatus.

\section{INTRODUCTION}

The papaya mealybug, Paracoccus marginatus Williams and Granara de

*Correspondence email:

okekesidney@gmail.com
Willink, is a polyphagous hemipteran pest that infests several host plants, including economically important tropical fruits, vegetables and ornamentals (Tanwar et al., 2010). It is believed to be native to Mexico 
and/or Central America but has never attained pest status, probably due to the presence of an endemic natural enemy complex in the native home (Miller et al., 1999).

Mealybugs constitute a very important pest group with highly varied host range from over 25 plant families including economic and weedy plants in genera such as Acacia, Acalypha, Ananas, Annona, Bidens, Capsicum, Hibiscus, Ipomoea, Mangifera, Manihot, Persea, Plumeria, Punica, Solanum and Vigna (Ben-Dov, 2008). Characteristically, they suck the sap of the host plants and weaken it making the leaves crinkled, yellowish and wither. Sooty mould develops on the honeydew excreted by mealybugs which cover the leaves, fruits and stems; impeding photosynthesis and gaseous exchange. Heavy infestations often cause the papaya plant to die within a few months (Heu et al., 2007). Due to the wide host range, the economic impact of infestation is considered to be high.

Paracoccus marginatus was first reported in Africa in Ghana in 2009 (Cham et al., 2011), in South and South East Asian regions between 2008 and 2009. The insect was also reported in Java, Indonesia in May 2008 from where it spread to Bali and Sulawesi (Muniappan et al., 2008; 2009). In July 2008, the papaya mealy bug was reported in the Colombo and Gampaha districts of Sri Lanka (Galanihe et al., 2010). The pest was also reported in Manila, Philippines in 2008; Joyedpur, Bangladesh and Phnom Penh, Cambodia in 2010 as well as in Thailand in 2010 (Galanihe et al., 2010). Thus, the status of this insect pest has risen to a significant level of importance.

Since the first report in Africa in 2009, the papaya mealybug has raised great concern especially in Ghana, where an estimated $85 \%$ of papaya farms were devastated causing about $65 \%$ yield losses.
The potential economic and ecological impacts of an outbreak in Nigeria could therefore be devastating considering the nation's production capacity. Nigeria produces $94 \%$ of the papaya from West Africa (FAO, 2010; Georgen et al., 2011). The food species that polyphagous insects feed on varies and this has been reported to influence the life history parameters such as developmental time and survival of the insect (Amarasekare, et al. 2008; Awmack and Leather 2002).

There are however reports that the pest has been reported on papaya since 2012 in Ibadan, South-western Nigeria (Umeh, pers comm.). Currently, there is very little information on the potential of the papaya mealybug to infest other economic plants as well as on its life history and interactions with other host plant species in Nigeria. Yet, this is important for the formulation of a meaningful pest management programme. The objective of this study was to evaluate the potential of selected crops as suitable food host of $P$. marginatus in Nigeria.

\section{MATERIALS AND METHODS}

The study was conducted at the Crop Research Garden and Entomology Research Laboratory of the Department of Crop Protection and Environmental Biology, University of Ibadan, Ibadan, Nigeria at ambient conditions $\left(27 \pm 2^{0} \mathrm{C}, 70 \pm 5 \% \mathrm{RH}\right.$ and 12:12 hour photoperiod).

\section{Insect Culture}

Pawpaw fruits infested with $P$. marginatus were collected from the Biological Control Unit of National Horticultural Research Institute (NIHORT), Idi-Ishin, Jericho, Ibadan. The culture was maintained at the Entomology Research Laboratory of the Department of Crop Protection and Environmental Biology University of Ibadan 
where a larger culture was raised on 8-12 weeks old pawpaw seedlings. The insects were carefully placed on the seedlings and allowed to mate and reproduce.

\section{Source of Planting Materials}

The potential host crops seedlings evaluated in the study are listed in Table 1. Carica papaya and Psidium guajava seedlings were obtained from NIHORT while Solanum lycopersicum and Abelmoschus esculentus seeds were purchased at Premier seeds,
Ibadan. Manihot esculenta stem cuttings were purchased from Eagle seeds, Ibadan while the Tectona grandis seedlings were obtained from the Department of Forest Resources Management, University of Ibadan. One seed was sown per pot of polythene bag containing $2 \mathrm{~kg}$ soil collected from the Crop Research Garden of the Department of Crop Protection and Environmental Biology, University of Ibadan, Ibadan.

Table 1: List of crops evaluated as host plants

\begin{tabular}{llll}
\hline Scientific name & Common name & Family & Type \\
\hline Carica papaya $\mathrm{L}^{*}$ & Pawpaw & Caricaceae & Fruit \\
Solanum lycopersicum L\# & Tomato & Solanaceae & Fruit \\
Manihot esculenta Crantz \# & Cassava & Euphorbiaceae & Root and Tuber \\
Psidium guajava $\mathrm{L}^{*}$ & Guava & Myrtaceae & Fruits \\
Abelmoschus esculentus L.\# & Okra & Malvaceae & Fruit vegetable \\
Tectona grandis $\mathrm{L}^{*}$ & Teak & Lamiaceae & Tree crop \\
\hline
\end{tabular}

Used at 8 weeks old, \# Used at 3 weeks old.

Evaluation of six tropical plant species as food host of $P$. marginatus in Ibadan, Nigeria

The six crops listed in Table 1 were evaluated for preference as food host by $P$. marginatus in the screen house. Six (6) screen cages $(1.80 \times 0.60 \times 1.50 \mathrm{~m})$ each with the six plants arranged in completely randomized design in three replicates were set up at the Crop Research Garden of the Department of Crop Protection and Environmental Biology (CPEB), University of Ibadan, giving a total of 18 plants per cage. The experiment was divided into two phases; free-choice and no-choice tests.

\section{Free-choice Test}

The six host plant species used were fitted to the edges of a $50 \mathrm{~cm}$ diameter cardboard and 100 third instar mealybugs were placed in the middle. This gave them equal opportunity to choose their preferred host. The number of mealybugs that migrated to specific host plants at 6, 24, 48 and 72 hours after the setup was recorded.

\section{No-choice Test}

For this test, 10 third instar crawlers were carefully placed directly on the leaves of the seedlings of different host plants using a camel hair brush. Their percentage survival at 96 hours after placement, were observed and recorded.

\section{Developmental biology study of $P$. marginatus on the six host crops}

The developmental biology was investigated at ambient conditions $\left(27 \pm 2{ }^{0} \mathrm{C} ; 70 \pm 5 \% \mathrm{RH}\right.$ and 12:12 hour photoperiod). Ovisacs of $P$. marginatus were carefully placed on the plants using a fine camel hair brush and their life cycle was studied by observing their 
development on a daily basis using a hand magnifying lens. Data were collected on duration of development of the various stages of its lifecycle and weight of adult on the different hosts.

\section{Data collection and Analysis}

Data collected were subjected to one way Analysis of Variance (ANOVA) using the statistical software DSAASTAT, 2014 version and significant means were separated using Duncan's Multiple Range Test at $\alpha .05$ probability level.

\section{RESULTS}

Free-choice test for host preference of $P$. marginatus on six plant species

More $P$. marginatus individuals were found on $C$. papaya than on other plants during the entire period of the free choice test (Table 2). There were significant differences in the population of $P$. marginatus at each period of observation (6 hrs, $24 \mathrm{hrs}, 48 \mathrm{hrs}$ and $72 \mathrm{hrs}$ ), with $C$. papaya having a significantly $(\mathrm{p}<0.05)$ higher population $(6.25,11.5,23$ and 27.5) across all time intervals respectively. This was followed closely by M. esculenta which recorded a population of
4, 11.25, 18 and 20.75 respectively at each period of observation. Solanum lycopersicum followed up with a population of $2.75,7.75$, 15 and $17,>P$. guajava with a population of 2.0, 5.25, 10.5 and $12.5>$ A. esculentus with a population of $1.25,4,8.5$ and 11.75 respectively. Tectona. grandis had the lowest population of $P$. marginatus with $0.75,3$, 7.25 and 10.0 all through the periods of observations. While the population of $P$. marginatus on the $C$. papaya remained significantly higher than the rest at 72 hours (27.5), there was no significant difference in the populations on $M$. esculenta and $S$. lycopersicum (20.7 and 17 respectively).

\section{No-choice test for host preference of $P$. marginatus on six host species}

Percentage survival of $P$. marginatus under no-choice test for host preference is presented in Fig 1. Survival was highest in C. papaya $(86.5 \%)$ and $M$. esculanta (77.1\%). This was followed by $S$. lycopersicum $(62.1 \%)$, A. esculentus $(46.2 \%)$ and $P$. guajava $(38.5 \%)$. Tectona grandis (29.2) had the lowest percentage surviving $P$. marginatus after $96 \mathrm{hrs}$.

Table 2: Population of $P$. marginatus on different host species under free-choice test for host preference at CPEB, University of Ibadan (Mean \pm S.E)

\begin{tabular}{lllll}
\hline Crops & 6 hours & $\mathbf{2 4}$ hours & $\mathbf{4 8}$ hours & $\mathbf{7 2}$ hours \\
\hline Carica papaya & $6.25 \pm 1.5 \mathrm{a}$ & $11.50 \pm 2.2 \mathrm{a}$ & $23.00 \pm 3.5 \mathrm{a}$ & $27.50 \pm 2.9 \mathrm{a}$ \\
Solanum lycopersicum & $2.75 \pm 0.7 \mathrm{ab}$ & $7.75 \pm 0.6 \mathrm{ab}$ & $15.00 \pm 1.7 \mathrm{~b}$ & $17.00 \pm 1.3 \mathrm{~b}$ \\
Manihot esculenta & $4.00 \pm 0.7 \mathrm{ab}$ & $11.25 \pm 1.0 \mathrm{a}$ & $18.00 \pm 1.2 \mathrm{~b}$ & $20.75 \pm 1.3 \mathrm{~b}$ \\
Psidium guajava & $2.00 \pm 0.4 \mathrm{~b}$ & $5.25 \pm 0.6 \mathrm{bc}$ & $10.50 \pm 0.3 \mathrm{c}$ & $12.50 \pm 0.4 \mathrm{c}$ \\
Abelmoschus esculentus & $1.25 \pm 0.2 \mathrm{~b}$ & $4.00 \pm 0.7 \mathrm{bc}$ & $8.50 \pm 0.2 \mathrm{c}$ & $11.75 \pm 1.2 \mathrm{c}$ \\
Tectona grandis & $0.75 \pm 0.2 \mathrm{~b}$ & $3.00 \pm 0.7 \mathrm{c}$ & $7.25 \pm 0.4 \mathrm{c}$ & $10.00 \pm 1.4 \mathrm{c}$ \\
\hline
\end{tabular}

Mean values \pm standard error within a column followed by the same letter(s) are not significantly different at $\mathrm{p}>0.05$ using Duncan's Multiple Range Test (DMRT). 


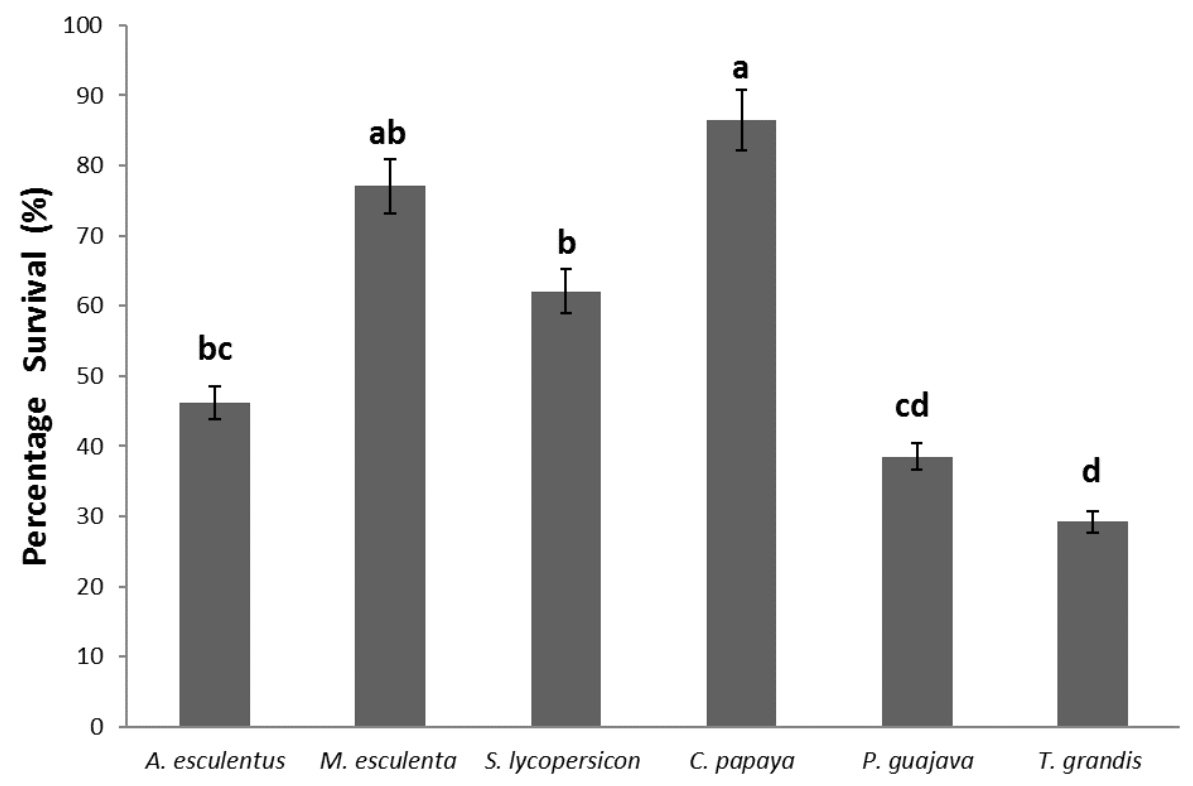

Figure 1: Percentage survival of $P$. marginatus on different host species under no-choice test for host preference at CPEB, University of Ibadan

Bars on which the same letters are shown are not significantly different at $\alpha .05$ using Duncan's Multiple Range Test (DMRT).

\section{Lifecycle of $\boldsymbol{P}$. marginatus on Six Different Host Species}

The mean number of days taken for $P$. marginatus to develop on six host species at the University of Ibadan is presented in Table 3. For all crops, development of eggs generally occurred within 6 days with the shortest $(6.12 \pm 0.1)$ and longest $(6.82 \pm 0.3)$ egg development duration occurring in pawpaw and tomato seedlings respectively. No significant differences $(\mathrm{p}>0.05)$ were observed amongst the time taken for $P$. marginatus egg to develop into first instar on all crop types. Development of first instar larvae of $P$. marginatus was shortest $(5.90 \pm 0.3)$ in pawpaw and longest $(6.81 \pm 0.5)$ in teak. There was a significant difference $(\mathrm{p}<0.05)$ between 1st instar developmental period on pawpaw and teak. Other crops did not show any significant difference in first instar developmental time $(\mathrm{p}>0.05)$ from pawpaw or teak. Development of 2nd instar larvae was generally shorter for females than males in all crop types. A significant difference $(\mathrm{p}<0.05)$ was observed in the time taken for 2 nd instar larvae males to develop on pawpaw $(6.38 \pm 0.5)$ compared to Okra $(7.01 \pm 0.4)$ or Teak $(7.32 \pm 0.3)$. All these 3 crops did not differ significantly $(\mathrm{p}<0.05)$ in developmental time of male 2 nd instar larvae when compared with tomato, cassava and guava. The developmental time of 2ndinstar female larvae did not however differ significantly amongst all crops. Unlike the 2nd instar larvae, the development of 3rd instar female larvae was generally longer than that of males in all crop types. The lowest developmental periods for male and female $3^{\text {rd }}$ instar larvae were observed in cassava $(3.51 \pm 0.4 ; 5.7 \pm 0.4$ respectively) and pawpaw $(3.72 \pm 0.4 ; 5.82 \pm 0.5$ respectively) while the highest values $(4.91 \pm 0.1 ; 6.32 \pm 0.6$ respectively) were observed in teak. The developmental time of $3^{\text {rd }}$ instar male $P$. marginatus on cassava and pawpaw were significantly lower $(p>0.05)$ than those of 
guava, okra and teak but not from tomato. On the contrary, developmental time of 3rd instar female $P$. marginatus on cassava and pawpaw were not significantly different ( $>0.05)$ from guava and okra. A similar trend was observed in the developmental time of male 4th instar larvae on all crop types.

Total developmental period of male and female $P$. marginatus from egg to adult was shortest in pawpaw $(25.91 \pm 0.6$ and $23.52 \pm 0.1$ respectively) and longest in teak $(30.62 \pm 0.80$ and $25.76 \pm 0.4)$. The total developmental period of male $P$. marginatus on pawpaw was significantly lower than those of tomato, guava okra and teak but not cassava. Similarly, the total developmental period for female $P$. marginatus on pawpaw was significantly lower than okra and teak, but did not differ significantly from cassava, tomato and guava.

Table 4 shows the mean weight of adult $P$. marginatus reared on different host species. The highest weight of $3.90 \mathrm{mg}$ was recorded on $M$. esculanta. Adults reared on C. papaya had a mean weight of $3.58 \mathrm{mg}$. The lowest mean weight of adult $P$. marginatus was recorded on $T$. grandis $(2.98$ $\mathrm{mg}$ ). Mean adult weights of $3.45 \mathrm{mg}, 3.20 \mathrm{mg}$ and $3.08 \mathrm{mg}$ were recorded on A. esculentus, $P$. guajava and $S$. lycopersicum respectively. However, there was no significant difference in the mean weight of adult $P$. marginatus reared on all six crop types.

Table 3: Duration of development (Days) of $P$. marginatus reared on six host species at CPEB, University of Ibadan

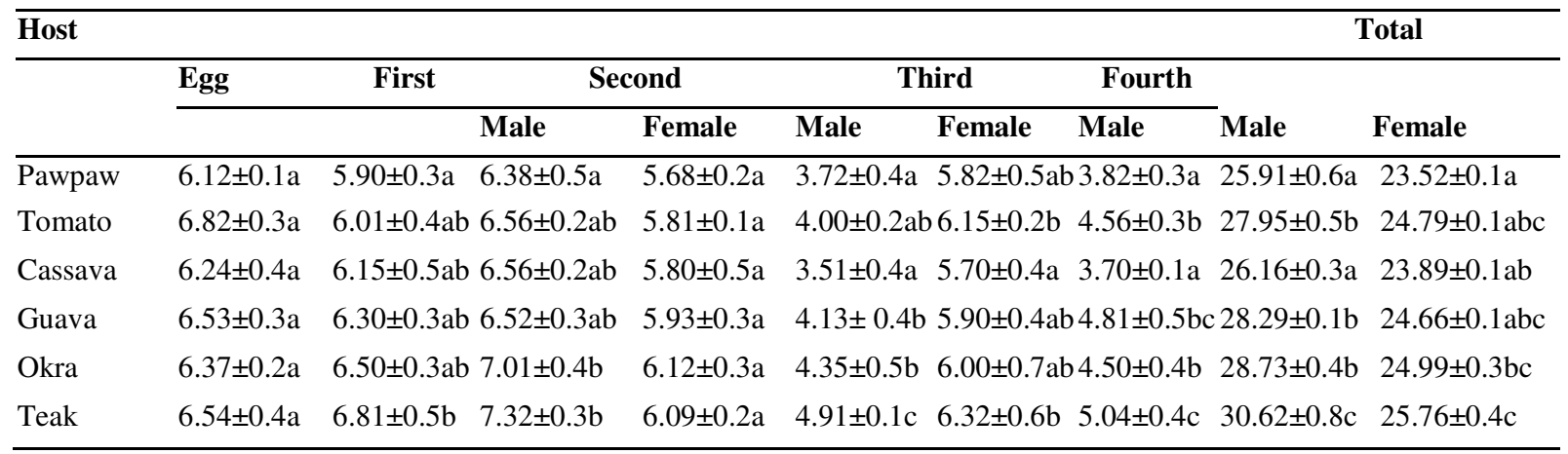

Means values \pm Standard error within a column followed by the same letter(s) are not significantly different ( $p$ > 0.05) using Duncan's Multiple Range Test (DMRT).

Table 4: Mean weight of adult P. marginatus reared on different hosts species at CPEB, University of Ibadan

\begin{tabular}{ll}
\hline Crops & Weight $(\mathbf{m g})$ \\
\hline Solanum lycopersicum $\mathrm{L}$ & $3.08 \pm 0.5 \mathrm{a}$ \\
Carica papaya $\mathrm{L}$ & $3.58 \pm 0.2 \mathrm{a}$ \\
Abelmoschus esculentus $\mathrm{L}$ & $3.45 \pm 0.2 \mathrm{a}$ \\
Tectona grandis $\mathrm{L}$ & $2.98 \pm 0.4 \mathrm{a}$ \\
Manihot esculenta Crantz & $3.90 \pm 0.6 \mathrm{a}$ \\
Psidium guajava $\mathrm{L}$ & $3.20 \pm 0.4 \mathrm{a}$ \\
\hline
\end{tabular}

Mean values \pm Standard error followed by the same letters are not significantly different $(\mathrm{p}>0.05)$ using Duncan's Multiple Range Test (DMRT). 


\section{DISCUSSION}

Paracoccus marginatus preferred $C$. papaya followed by M. esculanta compared to the other hosts as revealed by the freechoice and no-choice tests for host preference. This was followed by $S$. lycopersicum, A. esculentus, and P. guajava. This agrees with the findings of Galanihe $e t$ al. (2010) and Muniappan et al. (2008) that $C$. papaya and $M$. esculanta are favoured food hosts of $P$. marginatus. Cham et al. (2011) also supported this and reported that the host preference of $P$. marginatus seemed to be influenced by the presence of latex.

Tectona grandis was the least suitable host plant among the six evaluated. Similarly, Marohasy (1997) was able to identify Gossypium hirsutum L., Ageratum houstonianum Miller, and Clerodendrum cunninghamii Benth as less suitable host plants for the development of Phenacoccus parvus compared to Lantana camara. This indicates that some hosts are not preferred.

Egg to adult emergence occurred in about 25-30 days for the males, and 23-25 days for the female on all plant species evaluated. Eggs were observed to be laid in an egg sac which is bigger than the body length and the incubation period took about 6-7 days. Similar biology observations were reported by Kumar et al. (2014); Miller and Miller (2002); Walker et al. (2011); Muniappan et al. (2009) and Singh and Beera (2010) who reported that the egglaying of $P$. marginatus was usually in a small white ovisac and egg hatching occurred in about 5-10 days. Females had three nymphal instars, while males had an additional pupa stage. Male had longer developmental periods than the females due to the additional pupa stage. This is in line with the findings of Walker et al. (2011), who reported three nymphal instars besides pupa and a winged adult stage in male $P$. marginatus.

Paracoccus marginatus seemed to be able to develop and survive on all the plant species, although the variation in number of days shows that of the six different host species, C. papaya and $M$. esculentus favoured its development the most. In polyphagous insects, life history can vary with the plant species it feeds on. Different plant species provide different nutritional quality and chemical constituents, which can affect the development, reproduction and survival of an insect. The differences observed in the life history of $P$. marginatus in the different plant species may be due to nutritive factors, allelochemical compounds, and physical differences in leaf structures (Amarasekare et al., 2008). As have been reported by other researchers, different host plant species have affected the life history parameters of other mealybug species. The developmental time of female Planococcus kraunhiae (Kuwana) was shorter when reared on germinated Vicia faba L. seeds than on leaves of a Citrus sp. L. and on Cucurbita maxima Duchesne, and it survived better when reared on germinated $V$. faba seeds than on citrus leaves (Narai and Murai, 2002). Longer pre-reproductive period and a higher progeny production were observed for Rastrococcus invadens Williams reared on different varieties of Mangifera indica L. (Bovida and Neuenschwander, 1995). The pink hibiscus mealybug, Maconellicoccus hirsutus (Green), was able to develop equally well on Cucurbita pepo L. as on C. maxima (Serrano and Lapointe, 2002).

\section{CONCLUSION}

It is important to know the developmental biology of an insect so as to understand its distribution and adopt an effective method of management. Apart from C. papaya, which 
is the most preferred food host, several other economically important crops on which it has ability to complete life cycle conveniently; such as $S$. lycopersicum L, $M$. esculenta Crantz, $P$. guajava L, A. esculentus $\mathrm{L}$ and $T$. grandis $\mathrm{L}$ are at serious risk. This underscores the need to search for a sustainable pest management procedure for the pest. The information obtained from this study is vital to the development of appropriate Integrated Pest Management (IPM) programme for the pest.

\section{ACKNOWLEDGEMENTS}

The authors thank the National Horticultural Research Institute, Ibadan, Nigeria (NIHORT) for providing the initial culture of mealybugs used for the research and also for fully funding this research through a collaborative project between NIHORT and International Institute for Tropical Agriculture (IITA) with Grant from the Swiss Agency for Development and Cooperation.

\section{REFERENCES}

Amarasekare, K. G., Mannion, C. M. Osborne, L. S. and. Epsky, N. D. (2008). Life history of Paracoccus marginatus (Hemiptera: Pseudococcidae) on four host plant species under laboratory conditions. Environmental Entomology 37: 630-635.

Awmack, C. S. and Leather, S. R. (2002). Host plant quality and fecundity in herbivorous insects. Annual Review of Entomology, 47(1), 817-844.

Ben-Dov, Y. (2008). ScaleNet, Paracoccus marginatus. 17 September (2008). http://www.sel.barc.usda.gov/catalogs/pseu doco/Paracoccusmarginatus.htm.

Boavida, C. and Neuenschwander, P. (1995). Influence of the host plant on the mango mealybug, Rastrococccus invadens. Entomology Exp. Appl. 76: 179-188.

Cham, D., Davis, H., Obeng-Ofori, D. and Owusu, E. (2011). Host Range of the
Newly Invasive Mealybug Species Paracocccus Marginatus Williams and Granara De Willink (Hemiptera: Pseudococcidae) in two Ecological Zones of Ghana. Research in Zoology 2011; 1(1): 1-7.

Food and Agriculture Organization Corporate Statistics Database (2013). Papaya production statistics: Economic and Social Department: The Statistical Division. Accessed on 16th August, 2015

Galanihe, L. D., Jayasundera, M. U. P., Vithana, A., Asselaarachchi, N. and Watson, G. W. (2010). Occurrence, distribution and control of papaya mealybug, Paracoccus marginatus (Hemiptera: Pseudococcidae), an invasive alien pest in Sri Lanka. Journal of Tropical Agricultural Research and Extension 13(3): 2010.

Georgen, G., Tamo, M., Bokonon-Ganta, A. H. and Neuenschwander, P. (2011). Papaya mealybug: a New Invading Pest in West Africa, Biocontrol News and Information www.researchgate.net/ publication/235922380.

Heu, R. A., Fukada, M. T. and Conant, P. (2007). Papaya mealybug, Paracoccus marginatus Williams and Granara de Willink (Hemiptera: Pseudococcidae). New Pest Advisory. 4(3). State of Hawaii Department of Agriculture, Honolulu, HI.

Kumar, V., Topagi, S. C., Rajendra-Prasad, B. Revanasidda, S., Tharini, K. B. and Ashok Kumar, C. T. (2014). Biology and management of mealybug, Paracoccus marginatus Williams and Granara de Willink on Jatropha curcas L. Journal of Applied and Natural Science 6 (2): 770-778

Marohasy, J. (1997). Acceptability and suitability of seven plant species for the mealybug Phenacoccus parvus. Entomol. Exp. Appl. 84: 239-246.

Miller, D. R., Williams, D. J. and Hamon, A. B. (1999). Notes on a new mealybug (Hemiptera: Coccoidea: Pseudococcidae) pest in Florida and the Caribbean: the papaya mealybug, Paracoccus marginatus 
Williams and Granara de Willink. Insecta Mundi 13: 179-181.

Miller, D. R. and Miller, G. L. (2002). Redescription of Paracoccus marginatus Williams and Granara de Willink (Hemiptera: Coccoidea: Pseudococ-cidae), including descriptions of the immature stages and adult male. Proceedings of the Entomological Society of Washington 104: 1-23. Quoted in Walker A, Hoy M, and Meyerdirk, D. E. 2003 Papaya Mealybug. Univ. Florida Featured Creatures. http://creatures.ifas.ufl.edu/fruit/mealybugs/ papaya_mealybug.htm (Accessed on 29 Sept 2008).

Muniappan, R, Shepard, B. M, Watson, G. W,. Carner, G. R, Sartiami, D, Rauf, A. and Hammig, M. D. (2009). First Report of the Papaya Mealybug, Paracoccus marginatus (Hemiptera: Pseudococcidae), in Indonesia and India, Journal of Agricultural Urban and Entomology 25(1): 37-40.

Muniappan, R., Shepard, B. M., Watson, G. W., Carner, G. R., Sartiami, D., Rauf, A. and Hammig, M. D. (2008). First report of the papaya mealybug, Paracoccus marginatus (Hemiptera: Pseudococcidae), in Indonesia and India. Journal of Agricultural Urban Entomology, 25 (1): 3740.
Narai, Y., and Murai, T. (2002). Individual rearing of the Japanese mealybug, Planococcus kraunhiae (Kuwana) (Homoptera: Pseudococcidae) on a germinated broad bean seeds. Applied Journal of Entomology and Zoology 37: 295-298.

Serrano, M. S. and. Lapointe, S. L. (2002). Evaluation of host plants and a meridic diet for rearing Maconellicoccus hirsutus (Hemiptera: Pseudococcidae) and its parasitoid Anagyrus kamali (Hymenoptera: Encyrtidae). Florida Entomol. 85: 417-425.

Singh, R. N. and Beera, S. (2010). Biology of papaya mealybug (Paracoccus marginatus) and its biological control in sericulture. Indian Silk, 49 (4): 6-7.

Tanwar, R. K, Jeyakumar, P. and Vennila, S. (2010). Papaya mealybug and its management strategies, Technical Bulletin 22, National Centre for Integrated Pest Management, New Delhi.

Walker, A., Hoy, M, and Meyerdirk, D. (2011). Papaya mealybug, Paracoccus marginatus Williams and Granara de Willink (Insecta: Hemiptera: Pseudococcidae). Florida Cooperative Extension Service, Institute of Food and agricultural Sciences, University of Florida, Gainesville, FL.
NJE Vol. 35: 135-143, 2019

Nigerian Journal of Entomology

Published by the Entomological Soc. of Nig.

www.esnjournal.com.ng

DOI.10.36108/NJE/9102/53.01.21

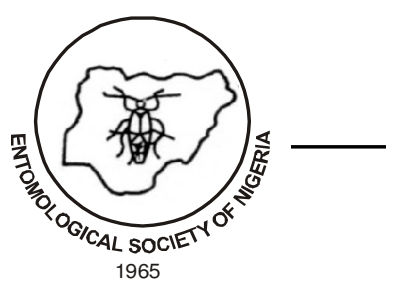

